\title{
Effects of a single mental chronometry training session in subacute stroke patients - a randomized controlled trial
}

\author{
Joachim Liepert ${ }^{1 *}$ (D), Jana Stürner ${ }^{1}$, Imke Büsching ${ }^{2}$, Aida Sehle ${ }^{1}$ and Mircea A. Schoenfeld ${ }^{3,4,5}$
}

\begin{abstract}
Background: Motor imagery training might be helpful in stroke rehabilitation. This study explored if a single session of motor imagery (MI) training induces performance changes in mental chronometry (MC), motor execution, or changes of motor excitability.
\end{abstract}

Methods: Subacute stroke patients $(n=33)$ participated in two training sessions. The order was randomized. One training consisted of a mental chronometry task, the other training was a hand identification task, each lasting 30 min. Before and after the training session, the Box and Block Test (BBT) was fully executed and also performed as a mental version which served as a measure of MC. A subgroup analysis based on the presence of sensory deficits was performed. Patients were allocated to three groups (no sensory deficits, moderate sensory deficits, severe sensory deficits). Motor excitability was measured by transcranial magnetic stimulation (TMS) pre and post training. Amplitudes of motor evoked potentials at rest and during pre-innervation as well as the duration of cortical silent period were measured in the affected and the non-affected hand.

Results: Pre-post differences of $M C$ showed an improved $M C$ after the $M I$ training, whereas $M C$ was worse after the hand identification training. Motor execution of the BBT was significantly improved after mental chronometry training but not after hand identification task training. Patients with severe sensory deficits performed significantly inferior in BBT execution and $\mathrm{MC}$ abilities prior to the training session compared to patients without sensory deficits or with moderate sensory deficits. However, pre-post differences of MC were similar in the 3 groups. TMS results were not different between pre and post training but showed significant differences between affected and unaffected side.

Conclusion: Even a single training session can modulate MC abilities and BBT motor execution in a task-specific way. Severe sensory deficits are associated with poorer motor performance and poorer MC ability, but do not have a negative impact on training-associated changes of mental chronometry. Studies with longer treatment periods should explore if the observed changes can further be expanded.

Trial registration: DRKS, DRKS00020355, registered March 9th, 2020, retrospectively registered

Keywords: Motor imagery, Mental chronometry, Stroke, Motor execution, Motor excitability

\footnotetext{
* Correspondence: j.liepert@kliniken-schmieder.de

'Department of Neurorehabilitation, Kliniken Schmieder, Zum Tafelholz 8,

78476 Allensbach, Germany

Full list of author information is available at the end of the article
}

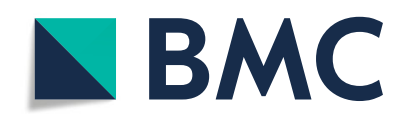

(c) The Author(s). 2020 Open Access This article is licensed under a Creative Commons Attribution 4.0 International License, which permits use, sharing, adaptation, distribution and reproduction in any medium or format, as long as you give appropriate credit to the original author(s) and the source, provide a link to the Creative Commons licence, and indicate if changes were made. The images or other third party material in this article are included in the article's Creative Commons licence, unless indicated otherwise in a credit line to the material. If material is not included in the article's Creative Commons licence and your intended use is not permitted by statutory regulation or exceeds the permitted use, you will need to obtain permission directly from the copyright holder. To view a copy of this licence, visit http://creativecommons.org/licenses/by/4.0/. The Creative Commons Public Domain Dedication waiver (http://creativecommons.org/publicdomain/zero/1.0/) applies to the data made available in this article, unless otherwise stated in a credit line to the data. 


\section{Background}

Motor imagery (MI) is a process that involves the mental execution of an action in the absence of movement, and it activates neural structures and processes similar to those activated when certain movements are actually performed [1, 2]. Different aspects contribute to MI abilities. The subject needs to be able to imagine actions in a three-dimensional space [3]. He or she should also be able to correctly estimate the duration of an imagined movement. This ability addressing the temporal structure of simulated actions is called mental chronometry (MC). MC involves the comparison of movement times during imagined and executed motor tasks [3]. It has been shown to be a reliable tool for screening for MI abilities [4]. A third aspect of MI is the vividness of motor imagery. This ability is typically addressed by selfassessment questionnaires (e.g., [5-7]).

Mental practice (MP) is a training method using MI elements and has been administered to stroke patients as an adjunct therapeutic approach for more than 15 years (e.g., [8, 9]). Current evidence suggests that most $[3,10-12]$ but not all stroke patients [13-16] have MI abilities similar to healthy subjects. However, controlled treatment trials have shown conflicting results. Recent reviews concluded that a trend in support of MP as a treatment option for upper extremity rehabilitation was evident [17] but that heterogeneity in methodological quality was too high to recommend MP in general [18].

The primary goal of this study was to investigate if even a single session of MI training produces detectable changes in $\mathrm{MC}$ performance, motor performance and motor excitability. In particular, we explored if changes in performance and/or excitability are task-specific. As secondary goal, we explored if the effects of a single MI training are influenced by impairments of sensory functions.

\section{Methods}

The same group of stroke patients participated in a MI training and, as a control condition, in a hand identification task training that addresses imaging (mental rotation) in three-dimensional space. Transcranial magnetic stimulation (TMS) techniques were used to assess changes of motor excitability. It has been shown that, during a motor imagery task, motor excitability increases specifically for those muscles involved in the task [19], Excitability changes are typically assessed by measuring the amplitudes of motor evoked potentials. In a preceding study we demonstrated that stroke patients with a severe sensory deficit had less motor excitability increases during a motor imagery task than stroke patients with a pure motor deficit [20]. In the present study, we did not examine motor excitability during but before and after the training period.

\section{Patients}

Altogether, 33 stroke patients (13 female, mean age: $63 \pm 11$ years, 16 with right-sided paresis, time since onset: $2.1 \pm 1.1$ months) were included after having given consent to participate in the study. Participants were recruited during inpatient neurological rehabilitation at Kliniken Schmieder, Allensbach, Germany. They stayed in the hospital for at least 4 weeks and had 3 treatment hours per day, 5 days a week. Treatments focused on hand and arm function for approximately $2 \mathrm{~h}$ per day and were similar for all patients regarding the amount and duration of therapy. For this trial, the patients in addition participated in a motor imagery training and a hand identification training. Both kinds of trainings have been used in stroke patients before [10, 15, 20, 21].

Our inclusion criteria were the ability to understand the instructions, the willingness to participate, an ischemic or hemorrhagic stroke $<6$ months ago as proven by cranial computed tomography or magnetic resonance imaging of the brain and the ability to grasp and release blocks that are typically used in a classical Box and Block Test [22]. The cubes have an edge length of 2.5 $\mathrm{cm}$. Subjects should be able to grasp and release at least 15 cubes. There were no restraints regarding time for accomplishing the task or the way of grasping.

Exclusion criteria were hemianopia, spatial neglect, anosognosia, severe other illness that could interfere with the ability to participate actively. Exclusion criteria for TMS application were a history of epileptic seizures, pregnancy, metallic implants in the brain and heart pace makers.

The location of the lesion was determined based on either magnetic resonance imaging or computer tomography. Lesions were stratified as being "subcortical" without any evidence of an involvement of cortical areas or as being "cortical/subcortical" with an involvement of cortical and subcortical areas.

Patient recruitments were started in March 2017 and, after reaching the estimated number of participants, terminated in July 2018.

\section{Measures \\ Somatosensory testing}

The sensory testing included detection of light touch, localization of touch and assessment of vibration sense as described earlier [15]. Detection of light touch was assessed with a cotton carrier at the fingertip of Digit II of the affected hand without visual control by the patient. It was noted if the patient felt the light touch on the affected hand immediately, only when applying pressure, or if the carrier couldn't be felt at all. To assess localization of touch, three different fingers of the affected hand were touched, again without visual control by the patient. Distinction was made if the patient 
detected the touch at all fingers correctly, if there was a mistake in one or two fingers, or no localization of touch was possible at all. A tuning fork with a scale of 0 to 8 served to test the vibration sense on the dorsal side of metacarpal joint of Digit II of the affected hand. 0 to 3 was defined as severe sensory loss, 4-6 as moderate sensory loss, and $7-8$ as no sensory deficit in vibration sense.

\section{Box and block test (BBT)}

A modified version of the BBT with 15 blocks was used for evaluation of motor performance and $\mathrm{MC}$ ability. The BBT is a widely used means of measuring upper extremity dexterity, including grasping, moving an object over a barrier and releasing it [22]. This test is frequently used as a measure of dexterity and has been shown to be valid and reliable [23-25]. It has been used to measure motor imagery abilities in preceding studies [20, 26]. The task requires the ability to grasp and release objects and to perform shoulder and elbow movements because the patient has to raise his arm in order to surmount the partition of the box with a height of $15 \mathrm{~cm}$.

The patients first perform the BBT mentally and then execute it as a motor task with one hand. For mental performance of the $\mathrm{BBT}$, the patient received an auditory go-signal from the examiner and indicated orally when he or she had completed the task. Motor imagery (MI) and motor execution (ME) of the BBT were first performed for the affected hand and then for the nonaffected one. The sequence of motor imagery and affected side first was chosen in order to avoid any influence and learning experience from motor execution and from the unaffected side. The times the patient needed to perform the task mentally and physically were measured by a stopwatch. MC ability was calculated as a ratio of ([motor execution time- motor imagery time]/ motor execution time) [15]. The reason for applying this ratio was to account for the influence of different $\mathrm{ME}$ times. For example, a difference of $3 \mathrm{~s}$ between $\mathrm{MC}$ and ME indicates a worse MC ability if ME takes $15 \mathrm{~s}$ than when it takes $30 \mathrm{~s}$. In dependence on whether ME or MI time was shorter, the ratio could either be a positive or a negative value. Since we were exclusively interested in the absolute difference, all ratios were expressed as positive values. The closer to zero a ratio is, the higher is the congruency between MI and ME. In the next step, pre-training ratios were subtracted from post-training ratios. In this case, the change of ratio was relevant: negative values indicated that post-training values had been closer to zero than pre-training ratios. Thus, negative values indicate an improved MC performance posttraining whereas positive values show a deterioration in $\mathrm{MC}$ performance.
BBT measures were done before and after both training sessions.

\section{Transcranial magnetic stimulation (TMS)}

TMS was performed with a circular coil. Recordings were taken from the first dorsal interosseous muscle (FDI) on both hands. Both hemispheres were studied consecutively. First, the optimal coil position, defined as the place where motor evoked potentials (MEPs) could be evoked with the lowest stimulus intensity, was determined. This coil position was marked with ink on the skin to ensure an exact repositioning of the coil throughout the experiment. Then, the motor threshold was identified. Resting motor threshold (MT) was defined as the stimulus intensity needed to produce MEPs with a size of $50-100 \mu \mathrm{V}$ in 5 out of 10 consecutive trials during complete muscle relaxation [27].

Transcranial magnetic stimulus intensity was set at $130 \%$ of the individual motor threshold. Six motor evoked potentials were recorded with the target muscle at rest. Another six MEPs as well as the cortical silent period (cSP) were collected during pre-innervation of the target muscle with approximately $20 \%$ of the maximum voluntary contraction force.

Recordings were stored (Viking IV, Viasys Comp.) and analysed off-line. MEPs were measured peak-to-peak, and a mean amplitude was calculated. The cSP duration was defined from the beginning of the MEP until the reoccurrence of EMG activity with an amplitude of at least $30 \%$ of the pre-stimulation EMG activity.

TMS was done before and after both training sessions.

The persons performing the measurements were blinded regarding the type of training.

The primary outcome measure was the change of $\mathrm{MC}$ ability, secondary outcomes measures were changes of ME abilities and changes of TMS parameters.

\section{Training Motor imagery training (MI)}

The BBT was used in the same way as described above. Patients were advised to exclusively imagine performing the task with the affected upper limb. A total of 15 blocks was placed in the box, arranged in 5 rows of 3 blocks. The patient received an auditory go-signal from the examiner and indicated orally when he or she had completed the task. The time between go-signal and stop-signal was measured with a stop-watch and recorded. This procedure was repeated as often as possible until $30 \mathrm{~min}$ were over. The patient did not receive any information about his or her level of performance. We chose to give no immediate feedback in order to imitate the typical clinical setting when MI is used as an add-on therapy. 


\section{Hand identification task training (HIT)}

In this mental rotation task, the subject watches a hand that is displayed in 8 different orientations on a PC screen and has to decide whether it is a right or a left hand by pressing the appropriate button on the keypad. Altogether, 40 hand images per run were presented, with four runs being performed. The results were analyzed with respect to the correctness of the answer and the time interval between target presentation and button press (response time). Patients used their unaffected hand to press the button.

Both trainings were performed for $30 \mathrm{~min}$. The sequence of trainings (first MI training followed by HIT training or vice versa) was randomized for each patient. Randomization was done by a person otherwise not involved in the study. A closed envelope that contained the information about the sequence for each single patient was given to the persons that performed the training sessions.

A minimum of 3 days was chosen as the interval between the sessions.

\section{Subgroups according to the degree of sensory impairment}

Based on sensory assessments the patients were subdivided into three groups. Group 1 patients did not have any sensory deficits. Group 2 comprised patients with mild to moderate sensory loss while group 3 was formed by the patients with severe sensory loss.

\section{Statistical analysis}

Statistical calculations were performed with IBM SPSS, version 25. A Shapiro Wilk test was performed to analyze if the data show a normal distribution. Only the ratios (ME-MI)/ME showed a normal distribution. BBT results and the TMS parameters were not normally distributed. For analysis of the non-normally distributed data Friedman tests were performed. Affected and nonaffected side were calculated separately. The ratios were analyzed with a paired sample $t$ test. For analysis of the 3 patient groups with different degrees of sensory deficits an analysis of variance (ANOVA) was calculated for the normally distributed MC data. The non-normally distributed BBT motor execution data were analyzed with Kruskal-Wallis test and, as posthoc analysis, with Mann-Whitney tests.

The level of statistical significance was assumed with $p<0.05$.

\section{Results}

Clinically, 10 patients presented a pure motor disturbance, 18 patients had a moderate impairment of sensory functions and 5 patients suffered from severe sensory deficits. Radiological results indicated subcortical hemorrhage in 8 patients and ischemic strokes in 25 patients. Altogether, 22 patients had pure subcortical lesions, the other 11 patients showed an additional involvement of cortical areas.

\section{Mental chronometry ratios}

Calculation of pre-post differences of $\mathrm{MC}$ ratios showed that only the group that had performed the MC training had a smaller MC ratio after the intervention whereas $\mathrm{MC}$ ratios increased after HIT training (MI training: $-0.05 \pm 0.16$; HIT: $0.05 \pm 0.15$ ). This difference was significant $(p=0.015)$.

\section{BBT motor execution}

On the paretic side, a significant difference between pre and post values was found for MI training but not for HIT training (Table 1). However, post values did not differ significantly between both exercises $(p=0.699)$. No significant differences between pre and post values were found on the unaffected side.

\section{Sensory deficits}

The three subgroups of patients (no sensory deficit [Group 1], moderate deficit [Group 2], severe deficit [Group 3]) were analyzed in relation to BBT motor execution, $\mathrm{MC}$ abilities prior to the training sessions and $\mathrm{MC}$ pre-post differences.

The three groups differed significantly in their motor performance (Group 1; $19.1 \pm 3.8 \mathrm{~s}$; Group 2: $26.0 \pm 11.8$ s, Group 3: $45.8 \pm 14.6 \mathrm{~s} ; p<0.001$. Group 1 versus Group 2: $p=0.102$; Group 1 versus Group 3: $\mathrm{p}<0.001$; Group 2 versus Group 3: $\mathrm{p}<0.001$ ) and in their $\mathrm{MC}$ abilities prior to HIT training and MI training (Group 1: $0.27 \pm 0.17$; Group 2: $0.26 \pm 0.17$; Group 3: $0.41 \pm 0.15$; $\mathrm{F}=3.788 ; p=0.028$. Group 1 versus Group 3: $p=0.078$; Group 2 versus Group 3: $p=0.03$; Group 1 versus Group 2: not significant) but were not significantly different in the mental chronometry pre-post differences (Group 1: MI training: $-0.049 \pm 0.1$; HIT: $0.019 \pm 0.19$; Group 2: MI training: $-0.054 \pm 0.17$; HIT: $0.066 \pm 0.13$; Group 3: MI training: $-0.062 \pm 0.2$; HIT: $0.04 \pm 0.11$ ).

Table 1 Motor execution times, measured in seconds, before (pre) and after (post) a single session of mental chronometry training (MC) and hand identification training (HIT). Mean values \pm standard deviations are presented. n.s., not significant

\begin{tabular}{|c|c|c|c|c|}
\hline & \multicolumn{4}{|c|}{ Box and block test } \\
\hline & \multicolumn{2}{|l|}{ MC group } & \multicolumn{2}{|l|}{ HIT group } \\
\hline & Affected & Unaffected & Affected & Unaffected \\
\hline Pre & $27.4 \pm 12.7$ & $12.5 \pm 2.1$ & $27.3 \pm 14.4$ & $12.5 \pm 2.3$ \\
\hline post & $25.5 \pm 12.7$ & $12.5 \pm 2.6$ & $26.8 \pm 14.6$ & $12.3 \pm 2.4$ \\
\hline$P$ value (pre - post) & 0.006 & 0.67 (n.s.) & 0.199 (n.s.) & 0.41 (n.s.) \\
\hline
\end{tabular}




\section{Training}

MI training

In total, patients needed $22.1 \pm 9$ (mean \pm standard deviation) seconds for moving the 15 blocks mentally. A subdivision of the results into a first and a second half of the trials showed no significant difference (first half: $21.8 \pm 8.4$ s, second half: $22.3 \pm 9.7$ s; $p=0.35$ ).

\section{Hit}

In total, patients needed $3.2 \pm 1.1 \mathrm{~s}$ for deciding whether a right or a left hand was presented on the screen. The reaction time was significantly longer $(p<0.001)$ in the first run compared to the other runs (first run: $3.8 \pm 1.3$ $\mathrm{s}$, second run: $3.1 \pm 0.9 \mathrm{~s}$, third run: $3.2 \pm 0.8 \mathrm{~s}$, fourth run: $2.9 \pm 1 \mathrm{~s})$. No significant difference was found between runs 2, 3 and 4 .

Similarly, the number of correct responses was significantly lower in the first run compared to runs 3 ( $p=$ $0.006)$ and $4(p=0.002)$. There was no significant difference between runs 2,3 , and 4 . Mean percentage of correct response: run $1,80.4 \pm 13.4 \%$, run 2 , $81.8 \pm 20.9 \%$, run $3,86.6 \pm 15.7 \%$, run $4,86.9 \pm 16.4 \%$.

\section{TMS results (Table 2 )}

TMS was performed in 26 patients. Seven patients had to be excluded due to presence of an exclusion criterion.

MEP amplitudes at rest showed a significant difference between affected and unaffected side for MI training $(p=0.012)$ but not for HIT training $(p=0.052)$. No significant pre/post difference was found in either group.

MEP amplitudes during pre-innervation neither showed a significant difference between affected and unaffected side nor between pre and post values.

The cortical silent period showed significantly longer durations of the cSP in the affected side in both groups (MI training: $\mathrm{p}=0.01$; HIT training: $\mathrm{p}=0.012$ ). There were no significant differences between pre and post values.

\section{Discussion}

The current study provides two main results: First, a single MI training modulated MC abilities and was associated with an improvement of motor execution. Second, MC changes were task-specific. Following MI training, stroke patients showed an improved MC performance whereas MC performance deteriorated after hand identification training. On the one hand, this result suggests that it is possible to improve MC abilities by a specific training. On the other hand, the observation suggests that focusing on another mental ability, in this case the performance of mental rotations, might interfere with MC performance, thus leading to an inferior MC ability.

Several studies have demonstrated that a single training session can induce a measurable change in performance (e.g., [28-32]). Our result is in line with this evidence.

However, task specificity has been investigated less consistently. In general, task-specific repetitive training has been shown to improve upper limb functions (e.g., $[33,34])$. For motor imagery, a beneficial task-specific effect has also been described [35]. Our results provide further evidence for these findings. Notably, the exercises we used for comparison both address features of motor imagery. Thus, the control condition is more comparable to the main intervention than this has been the case in previous studies.

Interestingly, only after MI training a significant improvement of BBT motor execution was found. This finding suggests a task-specificity and indicates that even a single MI training may influence motor performance of the same task. In contrast, after HIT training, no significant improvement of the BBT motor execution was found. In future studies we will explore whether untrained motor tasks might also be enhanced after MI training.

Patients differed in their motor performance in relation to their sensory functions. Those without sensory deficits showed the best performance, those with severe sensory deficits the worst performance. This result replicates an earlier report [15]. We also replicated the finding that patients with the most severe sensory deficits had the worst $\mathrm{MC}$ ability prior to the training. However, the pre-post $\mathrm{MC}$ difference was similar in the three groups. Thus, it seems as if sensory deficits do not preclude the possibility to benefit from a motor imagery training. Nevertheless, this assumption needs to be verified in a larger group of patients with severe sensory impairments.

Table 2 Amplitudes of motor evoked potentials (MEP), measured in $\mathrm{mV}$, and duration of the cortical silent period (cSP), measured in ms, before (pre) and after (post) a single session of mental chronometry training (MC) and hand-identification training (HIT) in $n=26$ patients. Mean values \pm standard deviations are presented. Aff, affected side; unaff, unaffected side

\begin{tabular}{|c|c|c|c|c|c|c|c|c|c|c|c|c|}
\hline & $\begin{array}{l}\text { MC } \\
\text { MEP rest } \\
\text { aff }\end{array}$ & $\begin{array}{l}\text { MC } \\
\text { MEP rest } \\
\text { unaff }\end{array}$ & $\begin{array}{l}\text { HIT } \\
\text { MEP rest } \\
\text { aff }\end{array}$ & $\begin{array}{l}\text { HIT } \\
\text { MEP rest } \\
\text { unaff }\end{array}$ & $\begin{array}{l}\text { MC } \\
\text { MEP } \\
\text { active } \\
\text { aff }\end{array}$ & $\begin{array}{l}\text { MC } \\
\text { MEP } \\
\text { active } \\
\text { unaff }\end{array}$ & $\begin{array}{l}\text { HIT } \\
\text { MEP } \\
\text { active } \\
\text { aff }\end{array}$ & $\begin{array}{l}\text { HIT } \\
\text { MEP } \\
\text { active } \\
\text { unaff }\end{array}$ & $\begin{array}{l}\text { MC } \\
\text { cSP aff }\end{array}$ & $\begin{array}{l}\text { MC } \\
\text { cSP unaff }\end{array}$ & $\begin{array}{l}\text { HIT } \\
\text { cSP aff }\end{array}$ & $\begin{array}{l}\text { HIT } \\
\text { cSP unaff }\end{array}$ \\
\hline Pre & $0.53 \pm 0.5$ & $0.95 \pm 0.6$ & $0.48 \pm 0.5$ & $0.91 \pm 0.8$ & $4.0 \pm 2.2$ & $5.9 \pm 2.5$ & $4.5 \pm 2.7$ & $6.1 \pm 2.6$ & $208.0 \pm 67.8$ & $137.7 \pm 39.2$ & $224.4 \pm 71.3$ & $138.4 \pm 42.2$ \\
\hline post & $0.65 \pm 0.6$ & $1.14 \pm 0.6$ & $0.62 \pm 0.6$ & $1.3 \pm 1.1$ & $4.2 \pm 2.4$ & $6.4 \pm 3.3$ & $4.4 \pm 2.7$ & $6.3 \pm 2.4$ & $200.4 \pm 60.7$ & $137.0 \pm 46.6$ & $214,8 \pm 73.5$ & $139.3 \pm 45.1$ \\
\hline
\end{tabular}


We were unable to demonstrate changes of motor excitability after the interventions. In contrast, it has been shown repeatedly that motor excitability is modulated during an motor imagery task [20,36], thus suggesting that a single motor imagery training is not able to produce motor excitability changes that persist beyond the imagery session. In part, this may be due to a high variability of the data. However, the type of training we chose might also have an influence. A recent publication in which a single session of mirror therapy had been explored reported MEP increases in the affected limb after the training [37]. Apart from the different types of intervention, patient group characteristics might also contribute to this difference in MEP results.

In accordance with preceding studies, TMS results (MEP amplitudes and duration of the cSP) indicated significant differences between affected and unaffected side. (e.g., [38-40]).

Limitations of this study are that patients with severe motor deficits were not included and that it is not yet known if the improvements of motor functions are restricted to BBT performance or can be transferred to untrained motor tasks as well.

\section{Conclusions}

The current study provides evidence that a single training session of mental chronometry can improve mental chronometry abilities and motor performance in a taskspecific way. Based on this result, we hypothesize that a series of MC training sessions could strengthen the effect seen after a single session. Such a strengthened effect might then have the potential to further translate into improved motor execution.

\section{Abbreviations \\ Aff:: Affected; ANOVA: Analysis of variance; BBT: Box and block test; CSP: Cortical silent period; EMG: Electromyography; FDI: First dorsal interosseous; HIT: Hand identification task; MC: Mental chronometry; ME: Motor execution; MEP: Motor evoked potential; MI: Motor imagery; ms: Milli seconds; mV: Milli volt; MT: Motor threshold; TMS: Transcranial magnetic stimulation; Unaff.: Unaffected; $\mu \mathrm{V}$ : Micro volt}

\section{Acknowledgements}

The authors would like to thank all the patients who were willing to participate in the study.

\section{Authors' contributions \\ $J \mathrm{~L}$ and AMS developed the study design. JS, IB and AS searched for eligible participants. IB and JL performed the training sessions. AS and JS were blinded for the type of training and performed the pre- and post- assessments. AS and JS analyzed the raw data. JS and JL performed the stat- istical analysis. JL wrote the first draft of the manuscript, JS, IB, AS and AMS revised the manuscript. All authors have read and approved the final version of the manuscript.}

\section{Funding}

The study was funded by the Lurija Institute for Rehabilitation Science and Research (Inhouse funding). Funding consisted of providing the salary for IB, JS and AS. The funder had no role in the design of the study, the collection, analysis, and interpretations of data, or in writing the manuscript.

\section{Availability of data and materials}

The datasets used and/or analysed during the current study are available from the corresponding author on reasonable request.

\section{Ethics approval and consent to participate}

The study was approved by the Ethical committee of the University of Constance. Written informed consent was obtained from all participants after oral and written information was provided.

\section{Consent for publication}

Not applicable.

\section{Competing interests}

The authors declare that they have no competing interests.

\section{Author details}

'Department of Neurorehabilitation, Kliniken Schmieder, Zum Tafelholz 8 , 78476 Allensbach, Germany. ${ }^{2}$ Rehaklinik Bellikon, Bellikon, Switzerland. ${ }^{3}$ Department of Neurorehabilitation, Kliniken Schmieder, Heidelberg, Germany. ${ }^{4}$ Department of Experimental Neurology, Medical Faculty, Otto-von-Guericke University Magdeburg, Magdeburg, Germany. ${ }^{5}$ Department of Behavioral Neurology, Leibniz Institute for Neurobiology, Magdeburg, Germany.

Received: 29 March 2020 Accepted: 5 October 2020

Published online: 22 October 2020

\section{References}

1. Jeannerod $M$, Decety J. Mental motor imagery: a window into the representational stages of action. Curr Opin Neurobiol. 1995;5(6):727-32.

2. Hétu S, Grégoire M, Saimpont A, Coll MP, Eugène F, Michon PE, Jackson PL. The neural network of motor imagery: an ALE meta-analysis. Neurosci Biobehav Rev, 2013:37(5):930-49.

3. Malouin F, Richards CL. Mental practice for relearning locomotor skills. Phys Ther. 2010;90:240-51.

4. Malouin F, Richards CL, Durand A, Doyon J. Reliability of mental chronometry for assessing motor imagery ability after stroke. Arch Phys Med Rehabil. 2008;89(2):311-9.

5. Malouin F, Richards CL, Durand A, Doyon J. Clinical assessment of motor imagery after stroke. Neurorehabil Neural Repair. 2008;22(4):330-4.

6. Dettmers C, Benz M, Liepert J, Rockstroh B. Motor imagery in stroke patients, or plegic patients with spinal cord or peripheral diseases. Acta Neurol Scand. 2012;126(4):238-47.

7. Saimpont A, Malouin F, Tousignant B, Jackson PL. Assessing motor imagery ability in younger and older adults by combining measures of vividness, controllability and timing of motor imagery. Brain Res. 2015;1597:196-209.

8. Jackson PL, Lafleur MF, Malouin F, Richards C, Doyon J. Potential role of mental practice using motor imagery in neurologic rehabilitation. Arch Phys Med Rehabil. 2001;82(8):1133-41.

9. Zimmermann-Schlatter A, Schuster C, Puhan MA, Siekierka E, Steurer J. Efficacy of motor imagery in post-stroke rehabilitation: a systematic review. J Neuroeng Rehabil. 2008;5:8-14.

10. Johnson SH. Imagining the impossible: intact motor representations in hemiplegics. Neuroreport. 2000;11(4):729-32.

11. Simmons L, Sharma N, Baron JC, Pomeroy VM. Motor imagery to enhance recovery after subcortical stroke: who might benefit, daily dose, and potential effects. Neurorehabil Neural Repair. 2008:22(5):458-67.

12. Braun N, Kranczioch C, Liepert J, Dettmers C, Zich C, Büsching I, Debener S. Motor imagery impairment in postacute stroke patients. Neural Plast. 2017; 2017:4653256

13. Sirigu A, Duhamel JR, Cohen L, Pillon B, Dubois B, Agid Y. The mental representation of hand movements after parietal cortex damage. Science. 1996:273:1564-8.

14. Wu AJ, Hermann V, Ying J, Page SJ. Chronometry of mentally versus physically practiced tasks in people with stroke. Am J Occup Ther. 2010;64: 929-34

15. Liepert J, Büsching I, Sehle A, Schoenfeld MA. Mental chronometry and mental rotation abilities in stroke patients with different degrees of sensory deficit. Restor Neurol Neurosci. 2016;34(6):907-14. 
16. McInnes K, Friesen C, Boe S. Specific brain lesions impair explicit motor imagery ability: a systematic review of the evidence. Arch Phys Med Rehabil. 2016;97(3):478-89.

17. Kho AY, Liu KP, Chung RC. Meta-analysis on the effect of mental imagery on motor recovery of the hemiplegic upper extremity function. Aust Occup Ther J. 2014:61(2):38-48.

18. Guerra ZF, Lucchetti ALG, Lucchetti G. Motor imagery training after stroke: a systematic review and meta-analysis of randomized controlled trials. J Neurol Phys Ther. 2017:41(4):205-14.

19. Facchini S, Muellbacher W, Battaglia B, Boroojerdi B, Hallett M. Focal enhancement of motor cortex excitability during motor imagery: a transcranial magnetic stimulation study. Acta Neurol Scand. 2002;105(3): $146-51$.

20. Liepert J, Greiner J, Nedelko V, Dettmers C. Reduced upper limb sensation impairs mental chronometry for motor imagery after stroke: clinical and electrophysiological findings. Neurorehabil Neural Repair. 2012;26(5):470-8

21. Johnson SH, Sprehn G, Saykin AJ. Intact motor imagery in chronic upper limb hemiplegics: evidence for activity-independent action representations. J Cogn Neurosci. 2002;14(6):841-52.

22. Mathiowetz V, Volland G, Kashman N, Weber K. Adult norms for the box and block test of manual dexterity. Am J Occup Ther. 1985;39(6):386-91.

23. Desrosiers J, Bravo G, Hébert R, Dutil E, Mercier L. Validation of the box and block test as a measure of dexterity of elderly people: reliability, validity, and norms studies. Arch Phys Med Rehabil. 1994;75:751-5.

24. Platz T, Pinkowski C, van Wijck F, Kim ICH, di Bella P, Johnson G. Reliability and validity of arm function assessment with standardized guidelines for the Fugl-Meyer test, action research arm test and box and block test: a multicentre study. Clin Rehabil. 2005;19:404-11.

25. Chen HM, Chen CC, Hsueh IP, Huang SL, Hsieh CL. Test-retest reproducibility and smallest real difference of 5 hand function tests in patients with stroke. Neurorehabil Neural Repair. 2009;23:435-40.

26. Greiner J, Schoenfeld MA, Liepert J. Assessment of mental chronometry (MC) in healthy subjects. Arch Gerontol Geriatr. 2014;58(2):226-30.

27. Rossini PM, Burke D, Chen R, Cohen LG, Daskalakis Z, Di lorio R, et al. Noninvasive electrical and magnetic stimulation of the brain, spinal cord, roots and peripheral nerves: basic principles and procedures for routine clinical and research application. An updated report from an I.F.C.N. committee. Clin Neurophysiol. 2015;126(6):1071-107.

28. Liepert J, Graef S, Uhde I, Leidner O, Weiller C. Training-induced changes of motor cortex representations in stroke patients. Acta Neurol Scand. 2000; 101(5):321-6.

29. Takeuchi N, Tada T, Toshima M, Chuma T, Matsuo Y, Ikoma K. Inhibition of the unaffected motor cortex by $1 \mathrm{~Hz}$ repetitive transcranical magnetic stimulation enhances motor performance and training effect of the paretic hand in patients with chronic stroke. J Rehabil Med. 2008;40(4):298-303.

30. Zimerman M, Heise KF, Hoppe J, Cohen LG, Gerloff C, Hummel FC. Modulation of training by single-session transcranial direct current stimulation to the intact motor cortex enhances motor skill acquisition of the paretic hand. Stroke. 2012;43(8):2185-91.

31. Nepveu JF, Thiel A, Tang A, Fung J, Lundbye-Jensen J, Boyd LA, Roig M. A single bout of high-intensity interval training improves motor skill retention in individuals with stroke. Neurorehabil Neural Repair. 2017;31(8):726-35.

32. Arya KN, Verma R, Garg RK, Sharma VP, Agarwal M, Aggarwal GG. Meaningful task-specific training (MTST) for stroke rehabilitation: a randomized controlled trial. Top Stroke Rehabil. 2012;19(3):193-211.

33. French B, Thomas LH, Coupe J, McMahon NE, Connell L, Harrison J, Sutton CJ, Tishkovskaya S, Watkins CL. Repetitive task training for improving functional ability after stroke. Cochrane Database Syst Rev. 2016;11: CD006073.

34. Craje C, van der Graaf C, Lem FC, Geurts AC, Steenbergen B. Determining specificity of motor imagery training for upper limb improvement in chronic stroke patients: a training protocol and pilot results. Int J Rehabil Res. 2010;33(4):359-62.

35. Oostra KM, Oomen A, Vanderstraeten G, Vingerhoets G. Influence of motor imagery training on gait rehabilitation in sub-acute stroke: a randomized controlled trial. J Rehabil Med. 2015:47(3):204-9.

36. Cicinelli P, Marconi B, Zaccagnini M, Pasqualetti P, Filippi MM, Rossini PM. Imagery-induced cortical excitability changes in stroke: a transcranial magnetic stimulation study. Cereb Cortex. 2006;16:247-53.

37. Novaes MM, Palhano-Fontes F, Peres A, Mazzetto-Betti K, Pelicioni M, Andrade KC, Dos Santos AC, Pontes-Neto O, Araujo D. Neurofunctional changes after a single mirror therapy intervention in chronic ischemic stroke. Int J Neurosci. 2018;20:1-9.

38. Liepert J, Restemeyer C, Kucinski T, Zittel S, Weiller C. Motor strokes: the lesion location determines motor excitability changes. Stroke. 2005;36(12): 2648-53.

39. Choi TW, Jang SG, Yang SN, Pyun SB. Factors affecting the motor evoked potential responsiveness and parameters in patients with supratentorial stroke. Ann Rehabil Med. 2014;38(1):19-28.

40. Lamola G, Fanciullacci C, Sgherri G, Bertolucci F, Panarese A, Micera S, Rossi B, Chisari C. Neurophysiological characterization of subacute stroke patients: a longitudinal study. Front Hum Neurosci. 2016;10:574 eCollection 2016.

\section{Publisher's Note}

Springer Nature remains neutral with regard to jurisdictional claims in published maps and institutional affiliations.
Ready to submit your research? Choose BMC and benefit from:

- fast, convenient online submission

- thorough peer review by experienced researchers in your field

- rapid publication on acceptance

- support for research data, including large and complex data types

- gold Open Access which fosters wider collaboration and increased citations

- maximum visibility for your research: over $100 \mathrm{M}$ website views per year

At BMC, research is always in progress.

Learn more biomedcentral.com/submissions 